\title{
The Problem of Overweight and Obesity - Does Geographical Location Matter?
}

\author{
Klaudia Kukurová ${ }^{1,2}$ *, Dilsad Ahmed ${ }^{3}$, Jian Wang ${ }^{4}$, Min Liu ${ }^{5}$, Raul Calderon ${ }^{6}$, Suporntip Pupanead ${ }^{7}$, \\ Yongkoo $\mathrm{Noh}^{8}$, Rui Gao ${ }^{9}$, Jiaxi Hu${ }^{1}$, Yi Zhao ${ }^{1}$, Yang Yang Xie ${ }^{1}$, Wilfred Wong ${ }^{10}$, Walter Ho ${ }^{1}$, \\ Patrick Ip ${ }^{10}$
}

\author{
${ }^{1}$ Faculty of Education, University of Macao, Taipa, Macao SAR, China \\ ${ }^{2}$ Faculty of Physical Education and Sport, Comenius University in Bratislava, Bratislava 814 99, Slovakia \\ ${ }^{3}$ College of Public Health and Human Sciences, Oregon State University, Corvallis, 97331, Oregon, United States \\ ${ }^{4}$ College of Exercise and Health Science, Tianjin University of Sport, Tianjin, 301617, China \\ ${ }^{5}$ School of Physical Education and Educational Science, Tianjin University of Sport, Tianjin, 301617, China \\ ${ }^{6}$ Faculty of Sports Science, Kasetsart University Kamphaeng Saen Campus, Nakhon Pathom, 73140, Thailand \\ ${ }^{7}$ Faculty of Education and Development Sciences, Kasetsart University, Nakhon Pathom, 73140, Thailand \\ ${ }^{8}$ Department of Policy Development, Korean Institute of Sport Science, Seoul, 01794, Republic of Korea \\ ${ }^{9}$ College of Sport Training Sciences, Tianjin University of Sport, Tianjin, 301617, China \\ ${ }^{10}$ Department of Paediatrics and Adolescent Medicine, University of Hong Kong, Hong Kong, China
}

Received June 1, 2021; Revised August 5, 2021; Accepted September 8, 2021

\section{Cite This Paper in the following Citation Styles}

(a): [1] Klaudia Kukurová, Dilsad Ahmed, Jian Wang, Min Liu, Raul Calderon, Suporntip Pupanead, Yongkoo Noh, Rui Gao, Jiaxi Hu1, Yi Zhao, Yang Yang Xie, Wilfred Wong, Walter Ho, Patrick Ip , "The Problem of Overweight and Obesity - Does Geographical Location Matter?," Universal Journal of Public Health, Vol. 9, No. 5, pp. 208 - $217,2021$. DOI: 10.13189/ujph.2021.090502.

(b): Klaudia Kukurová, Dilsad Ahmed, Jian Wang, Min Liu, Raul Calderon, Suporntip Pupanead, Yongkoo Noh, Rui Gao, Jiaxi Hu1, Yi Zhao, Yang Yang Xie, Wilfred Wong, Walter Ho, Patrick Ip (2021). The Problem of Overweight and Obesity - Does Geographical Location Matter?. Universal Journal of Public Health, 9(5), 208 - 217. DOI: 10.13189/ujph.2021.090502.

Copyright $\subseteq 2021$ by authors, all rights reserved. Authors agree that this article remains permanently open access under the terms of the Creative Commons Attribution License 4.0 International License

\begin{abstract}
The number of people with overweight and obesity issues has been increasing rapidly worldwide. This increase is related to many factors including physical activity, social background, economic development, cultural practices, etc. This study examined the body mass index (BMI) of 25,373 children, aged 6-12 years, from four Asian cities to assess children's health status and the association of geographical location with BMI issues. BMI data were calculated and classified according to the WHO criteria. Differences in height, weight, and BMI were calculated for boys and girls from different cities. Cross-city analyses revealed significant differences: children from the cities in higher latitudes had the highest chances of problems with overweight and obesity, compared with those in latitudes close to equator. There were a greater number of obese boys than girls. The most rapid increase of overweight and obesity issues in children occurred from ages 8-10 years, suggesting that this was a critical period in their development. Our findings suggest a
\end{abstract}

geographical trend of a gradual increase in overweight and obesity issues from south to north. Weight management and physical activity programs for children aged 8-10 years could be effective for easing the increase among overweight and obesity.

Keywords Asian Cities, Anthropometry, Body Mass Index (BMI), Children's Health, Geographical Matter, Public Health

\section{Introduction}

The increase in the number of people with overweight and obesity has become almost a worldwide issue in the past three decades [1-3]. The focus on overweight and obesity is even more important during COVID-19 pandemic, since it is reported that obese people are at high 
risk of mortality from COVID-19 infection [4,5]. Being overweight and obese are associated with many physical and psychological health problems [3], as well as mortality [6]. Obesity, although more prevalent in developed countries, also occurs in developing countries or those of lower income [2,7]. A study by Ng et al. [2] predicted that the prevalence of overweight and obesity would likely continue to increase in the developing world. In fact, overweight and obesity have reached epidemic proportions in many Asian countries [8-10]. For example, in 2019, China reported that $46 \%$ of adults and $15 \%$ of children were obese or overweight [11]. Also, obesity-related disorders such as diabetes, hypertension, and cardiovascular diseases occur in younger ages among individuals in Asian countries than in Western countries [8] or it occurs at lower value of BMI in Asian versus populations [12]. The WHO recognizes this problem, and the expert consultation report [13] recommended lower Body Mass Index (BMI) cut-off points for determining overweight and obesity in Asia. Nevertheless, this strategy needs to consider the geographical effects and the living environment.

Many studies have pointed out that it is important to focus on overweight and obesity in children because there is evidence for an association between obesity in childhood and obesity in adulthood $[6,14,15]$. The family environment also plays a role; children are more likely to become obese if one of the parents is obese [16]. A high BMI value at the age of 6 years is significantly associated with high BMI later in life [17].

The obesity epidemic is growing among school-aged children at an alarming rate [18]. The prevalence of overweight and obesity among children and adolescents aged 5-19 years has risen dramatically, from only $4 \%$ in 1975 to over $18 \%$ in 2016 [3]. Globally, the number of overweight children under 5 years of age was estimated to be over 42 million in 2015. The Center for Disease Control [15] indicated that $18.4 \%$ of 6 - to 11 -year-olds are obese.

The prevalence and increase of this global issue of childhood obesity varies across countries. For this reason, it is important to investigate the problem and find a solution to the recent increase. Some authors $[17,19,20]$ have sought to identify the critical ages at which BMI shifts towards overweight and obesity. Observations suggest that there are two or three critical periods for the development or risk of obesity. Dietz [20] asserted that these periods are gestation and early infancy, the period of adiposity rebound that occurs at ages 5-7 years, and adolescence. According to another study, BMI reduces at 6-8 years of age, and then begins to increase again thereafter [19]. Geserick et al. [21] assessed BMI values in a large population from infancy to adolescence and found that more than $50 \%$ of the adolescents with obesity had been at least overweight from 5 years of age onwards; however, almost $90 \%$ of children who were obese at 3 years were obese or overweight at adolescence.

In this study, there was the attempt to determine the height, weight, BMI, and the prevalence of selected BMI categories among boys and girls in four Asian cities. Next, it focused on the critical period for children aged 6-12 during which overweight and obesity visibly and clearly increased, or the age at which the highest number of children were overweight or obese. The information from this study may help to explain the social phenomena and the structural differences of overweight and obesity development in children and assist in strategic planning of physical activities to help them become more active.

\section{Methods}

\subsection{Participants}

The sample population assessed in the current study consisted of 25,373 (13,224 male and 12,149 female) school-aged children living in the cities of Bangkok, Hong Kong, Seoul, and Tianjin. The number and percentage of children aged 6-12 years from the selected cities, according to sex and age, are provided in Table 1. This study lacked data on children aged 6 years from Seoul for both sexes. Age was calculated using the children's day of birth at the day when measurements were taken. There were seven age groups (6-12 years) as follows: age 6 (6.0 to 6.9 years), age 7 (7.0 to 7.9 years), ... age 12 (12.0 to 12.9 years). The age range of 6-12 years was chosen because it represents the pre-adolescent period and is likely to be favourable for the implementation of strategies to prevent overweight and obesity issues [22]. Data were collected from 2014 to 2017 through various research activities in different cities (2016, Bangkok; 2015, Hong Kong; 2014, Seoul, and 2017, Tianjin) all activities were approved by an appropriate institutional review board. The study was conducted in line with the Declaration of Helsinki (1975). The participation was voluntary and informed written consent form for participation was obtained from the parents of all children assessed in this study after the study objectives were clearly explained to the participants and their parents. If parents agreed to involve their child in the present study, they sign consent form. The height and weight information were mixed and coded by the research team to indicate the city origin. No one would be able to have any recognition of children's information. 
Table 1. Number of males and females among selected cities and ages

\begin{tabular}{|c|c|c|c|c|c|c|c|c|}
\hline Age & \multicolumn{2}{|c|}{ Bangkok } & \multicolumn{2}{c|}{ Hong Kong } & \multicolumn{2}{c|}{ Seoul } & \multicolumn{2}{c|}{ Tianjin } \\
\hline Gender & Boys & Girls & Boys & Girls & Boys & Girls & Boys & Girls \\
\hline 6 & 163 & 147 & 764 & 643 & 0 & 0 & 313 & 265 \\
\hline 7 & 196 & 160 & 1019 & 931 & 50 & 50 & 455 & 418 \\
\hline 8 & 271 & 341 & 1232 & 1143 & 50 & 50 & 471 & 419 \\
\hline 9 & 411 & 409 & 1238 & 1235 & 50 & 52 & 550 & 447 \\
\hline 10 & 432 & 247 & 1120 & 1144 & 50 & 50 & 424 & 377 \\
\hline 11 & 237 & 202 & 1092 & 1073 & 50 & 51 & 513 & 439 \\
\hline 12 & 418 & 570 & 1485 & 1144 & 50 & 50 & 120 & 92 \\
\hline Total & 2128 & 2076 & 7950 & 7313 & 300 & 303 & 2846 & 2457 \\
\hline$\%$ & 16.1 & 17.1 & 60.1 & 60.2 & 2.3 & 2.5 & 21.5 & 20.2 \\
\hline
\end{tabular}

\subsection{Research Tool}

Children's BMI was calculated as follows: child's weight in kilograms divided by child's height in meters squared $\left(\mathrm{kg} / \mathrm{m}^{2}\right)$. When the height and weight were measured, the children were barefoot, wearing light clothes, and not carrying any objects. Height was measured by stadiometer in centimetres and converted to meters. Weight was measured by scales, which had been calibrated prior to taking measurements. The BMI values were categorized as underweight, normal weight, overweight, and obese. These four categories were based on norms and indicators of the WHO [23]. This study analyzed the categories of overweight and obesity for estimating the critical age for the group of children in our sample.

\subsection{Statistical Analysis}

Data were analysed using SPSS software (version 23.0). The normality and homoscedasticity assumptions were checked respectively with the Kolmogorov-Smirnov and the Levene Tests. Frequency statistics and descriptive statistics (mean \pm standard deviation) were calculated for all children from different cities and gender. The t-test for independent samples and Anova test were used to calculate the differences in weight, height, and BMI. Chi squared was used to calculate the differences in distribution of categorical variables.

\section{Results}

In this study, $16.6 \%$ of the children were from Bangkok, $60 \%$ were from Hong Kong, $2.4 \%$ were from Seoul, and $21 \%$ were from Tianjin. Girls made up $48 \%$ of the participants and boys made up 52\%. The overall average age of boys was $9.22 \pm 1.90$ years and for girls it was $9.22 \pm 1.87$ years. The average ages for boys and girls by city were: from Bangkok $9.47 \pm 1.8$ years and $9.50 \pm 1.7$ years; from Hong Kong $9.28 \pm 1.9$ years and $9.24 \pm 1.9$ years; from Seoul $9.50 \pm 1.7$ years and $9.50 \pm 1.7$ years; and Tianjin $8.82 \pm 1.7$ years and $8.79 \pm 1.7$ years, respectively.

The overall mean height, weight, and BMI of all male participants $(\mathrm{N}=13,224)$ were $1.39 \mathrm{~m} \pm .14,36.37 \mathrm{~kg} \pm$ 13.0 and $18.32 \mathrm{~kg} / \mathrm{m}^{2} \pm 4.1$, respectively. The mean height, weight, and BMI of female participants $(\mathrm{N}=12,149)$ were $1.39 \mathrm{~m} \pm .14,34.32 \mathrm{~kg} \pm 11.62$, and $17.42 \mathrm{~kg} / \mathrm{m}^{2} \pm 3.65$. Statistically significant differences between boys and girls were found in height $(\mathrm{t}=2.209$; 95\% CI .0004 to .007 ; $\mathrm{p}<0.05$ and effect size $d=.03$ ), weight $(t=13.293 ; 95 \%$ CI 1.75 to 2.35; $\mathrm{p}<0.01$ and effect size $\mathrm{d}=.17$ ) and in BMI $(\mathrm{t}=18.567 ; 95 \%$ CI .806 to .996; $\mathrm{p}<0.01$ and effect size $\mathrm{d}=.23$ ). Table 2 shows the mean and standard deviation for height, weight and BMI among gender and cities. According to the Bonferroni post-hoc test for ANOVA, the most frequent significant differences in height, weight and BMI were observed between children from Tianjin and other cities. The children from Tianjin were statistically taller, heavier, and had higher BMI values (expect in the case of girls in comparison with Seoul only in BMI). All statistical differences among cities are shown in Table 2. Boys from Bangkok were statistically shorter and lighter than boys from other cities. In case of girls, the shortest and lighter girls were from Bangkok, however, there was no significant difference between these girls and those from Seoul in height and from Seoul and Hong Kong in weight. Additionally, girls from Hong Kong had the lowest value of BMI. In summary, the children form Tianjin and Seoul were heavier and had higher average BMIs than children from Bangkok and Hong Kong. 
Table 2. Anthropometrics parameters among gender and cities and results of ANOVA test

\begin{tabular}{|c|c|c|c|c|c|c|c|}
\hline Boys & Bangkok $^{\mathbf{1}}$ & HongKong $^{\mathbf{2}}$ & Seoul $^{\mathbf{3}}$ & Tianjin $^{\mathbf{4}}$ & Anova $^{\text {p value }}$ & Post-hoc \\
\hline Height & $1.34 \pm .13$ & $1.39 \pm .14$ & $1.38 \pm .12$ & $1.42 \pm .14$ & 160.674 & .00 & $1<2,3,4 ; 4>1,2,3$ \\
\hline Weight & $33.5 \pm 13.0$ & $35.5 \pm 12.4$ & $35.6 \pm 10.2$ & $40.1 \pm 14.0$ & 119,865 & .00 & $1<2,3,4 ; 4>1,2,3$ \\
\hline BMI & $18.1 \pm 4.5$ & $18.0 \pm 3.6$ & $18.4 \pm 3.0$ & $19.3 \pm 4.9$ & 79.255 & .00 & $4>1,2,3$ \\
\hline Girls & & & & & & & \\
\hline Height & $1.36 \pm .15$ & $1.39 \pm .13$ & $1.37 \pm .12$ & $1.41 \pm .14$ & 62.455 & .00 & $1<2,4 ; 4>1,2,3$ \\
\hline Weight & $33.6 \pm 12.6$ & $33.7 \pm 10.9$ & $34.6 \pm 9.8$ & $36.6 \pm 12.7$ & 40.030 & .00 & $4>1,2,3$ \\
\hline BMI & $17.7 \pm 4.0$ & $17.1 \pm 3.1$ & $17.9 \pm 2.9$ & $18.0 \pm 4.7$ & 40.257 & .00 & $2<1,3,4 ; 1<4$ \\
\hline
\end{tabular}

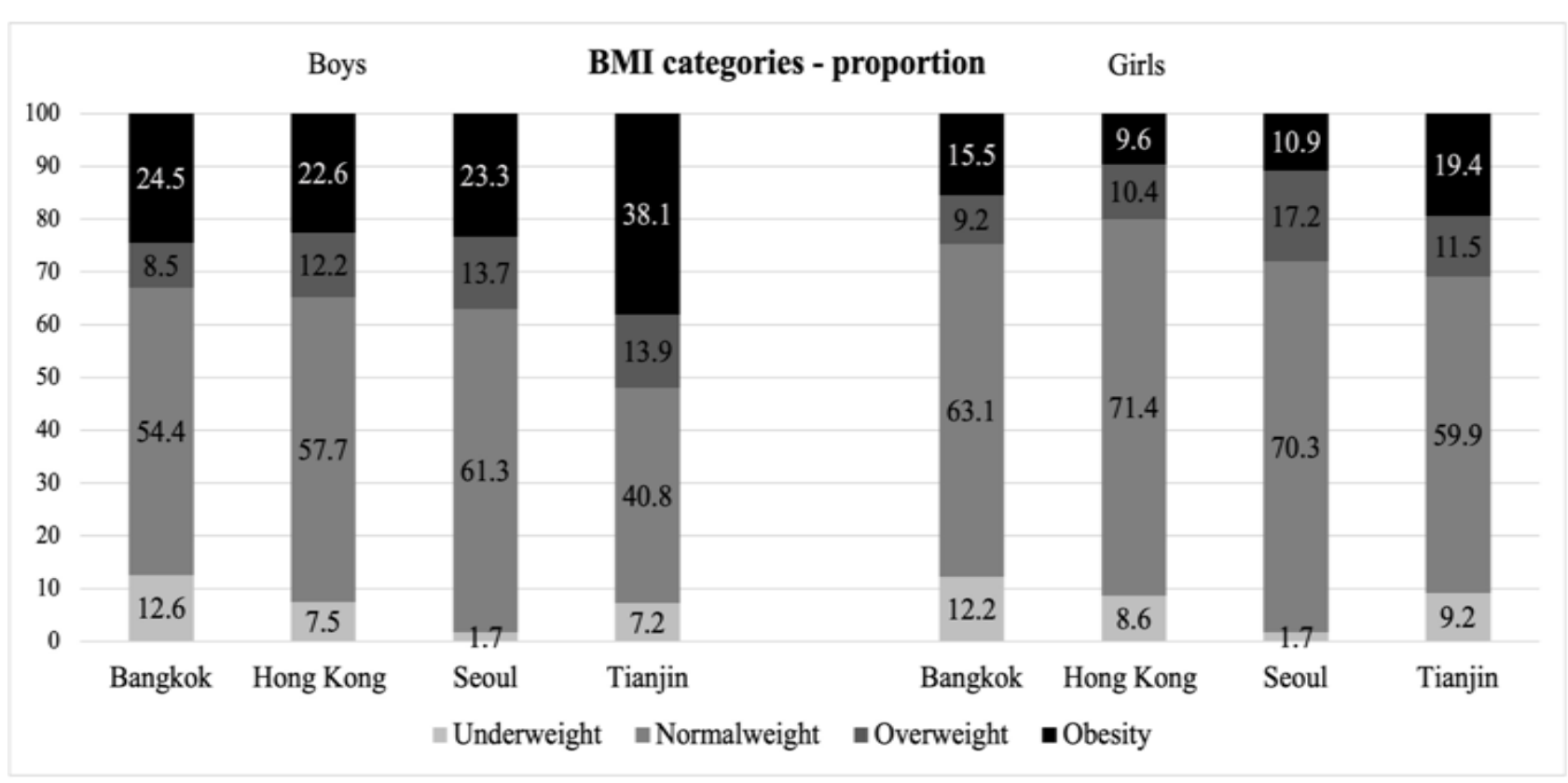

Figure 1. Proportion of BMI categories among genders and cities

The next task in the study was to observe the proportion of children in each BMI category. The BMI values were categorized according to WHO criteria [23]. The proportions for girls and boys are plotted in Figure 1. Significant differences in the proportions of boys and girls from different cities existed among BMI categories (chi squared 417.928, df $=9$; $\mathrm{p}<0.01$ for boys; chi-square 261.358, $\mathrm{df}=9 ; \mathrm{p}<0.01$ for girls). Seoul had the highest number of children in the Normal weight BMI category; Tianjin had the fewest. There was a significant difference in Normal weight (chi squared 6062.508, df 3, $\mathrm{p}<0.01$ for girls and chi square 6918.879, $\mathrm{df}=3, \mathrm{p}<0.01$ for boys) among cities. However, the children from Seoul were the least underweight, and the most underweight children for both genders were from Bangkok. There was also a significant difference among cities in the Underweight category (chi square 673.611, $\mathrm{df}=3, \mathrm{p}<0.01$ for boys and chi squared 768.823, df $=3, \mathrm{p}<0.01$ for girls). Overall, $26.3 \%$ of boys in our sample were obese and $12 \%$ were overweight, while $12.6 \%$ of girls were obese and $10.5 \%$ were overweight. Boys were at higher risk for being overweight or obese than girls. Tianjin faced the largest health challenge, with $52 \%$ of boys and $30.9 \%$ of girls obese or overweight. Seoul followed, with $37 \%$ of boys and $28.1 \%$ of girls overweight or obese. From 20\% to 33\% of children from Bangkok and Hong Kong were overweight or obese. There was a statistically significant difference between boys and girls among cities in the Overweight category (chi square 1226.865, $\mathrm{df}=3$, $\mathrm{p}<0.01$ for boys; chi square 881.736, $\mathrm{df}=3$, $\mathrm{p}<0.01$ for girls) and Obese category (chi square 1872.918, $\mathrm{df}=3, \mathrm{p}<0.01$ for boys; chi square 630.510 , $\mathrm{df}=3, \mathrm{p}<0.01$ for girls).

The aim of this study was to observe the trends of overweight and obesity among school-aged children from selected Asian cities. Figure 2 and Figure 3 show the trends in overweight and obesity in ages 6-12, among gender and cities, and overall trends among age and gender. At the age of $6,10.5 \%$ and $17.6 \%$ of boys were overweight and obese, respectively, and by age 12 , the numbers had increased to $13 \%$ and $21 \%$. At the age of 6 , $7.2 \%$ and $10.2 \%$ of girls were overweight and obese, respectively, and by age 12, these proportions had increased to $11.4 \%$ and $10.5 \%$.

The most overweight children in our study were from 
Tianjin and Seoul, and the least overweight were from Bangkok. The city with the highest number of obese boys was Tianjin. To estimate the critical age period for the increase in overweight and obesity, we calculated the overall curve for overweight children and determined the overall percentages of obese children (Figure 2 for boys and Figure 3 for girls). The proportion of overweight boys increased from age 8 years (10.6\%) until age 10 years (13.5\%); thereafter, there was a small drop of $1.1 \%$ between ages 10 and 11 years, followed by another increase $(+0.6 \%)$. The biggest increase was observed after ages $8-9$ years, in which the prevalence increased by $1.7 \%$. In the obesity category, in case of boys the overall curve was clearer. It increased slightly after age 6 years (17.6\%) but, after age 7 years (20.6\%), it increased by $5.8 \%$ and continued to increase until age 10 years (32.6\%), after which it reduced by $1.4 \%$ at age 11 years, and by age 12 years, reduced by another $10.5 \%$.
The leading cities for overweight and obese girls are Seoul and Tianjin. Similar to boys, the least overweight girls were from Bangkok. Girls ages 8-11 from Bangkok demonstrated higher proportions of obesity in comparison with other cities, but the proportions were still not as high as in Tianjin. The lowest proportions of obesity were among girls from Hong Kong. According to the overall curve, which presents the development trends of all overweight girls from the sample, the proportions continuously increased from ages 6-11 (7.2-12.7\%), followed by slight drop of $1.3 \%$. The biggest increase for girls was after age $8(+1.5 \%)$. For obesity, the estimation of critical period for developing obesity according to the overall curve is clearer. In girls, the critical period is from ages 7-10 (10.5-14.9\%), after which the proportion drops by $2.7 \%$. This critical period includes the same age group for boys. By age 12, 10.5\% of girls were obese.

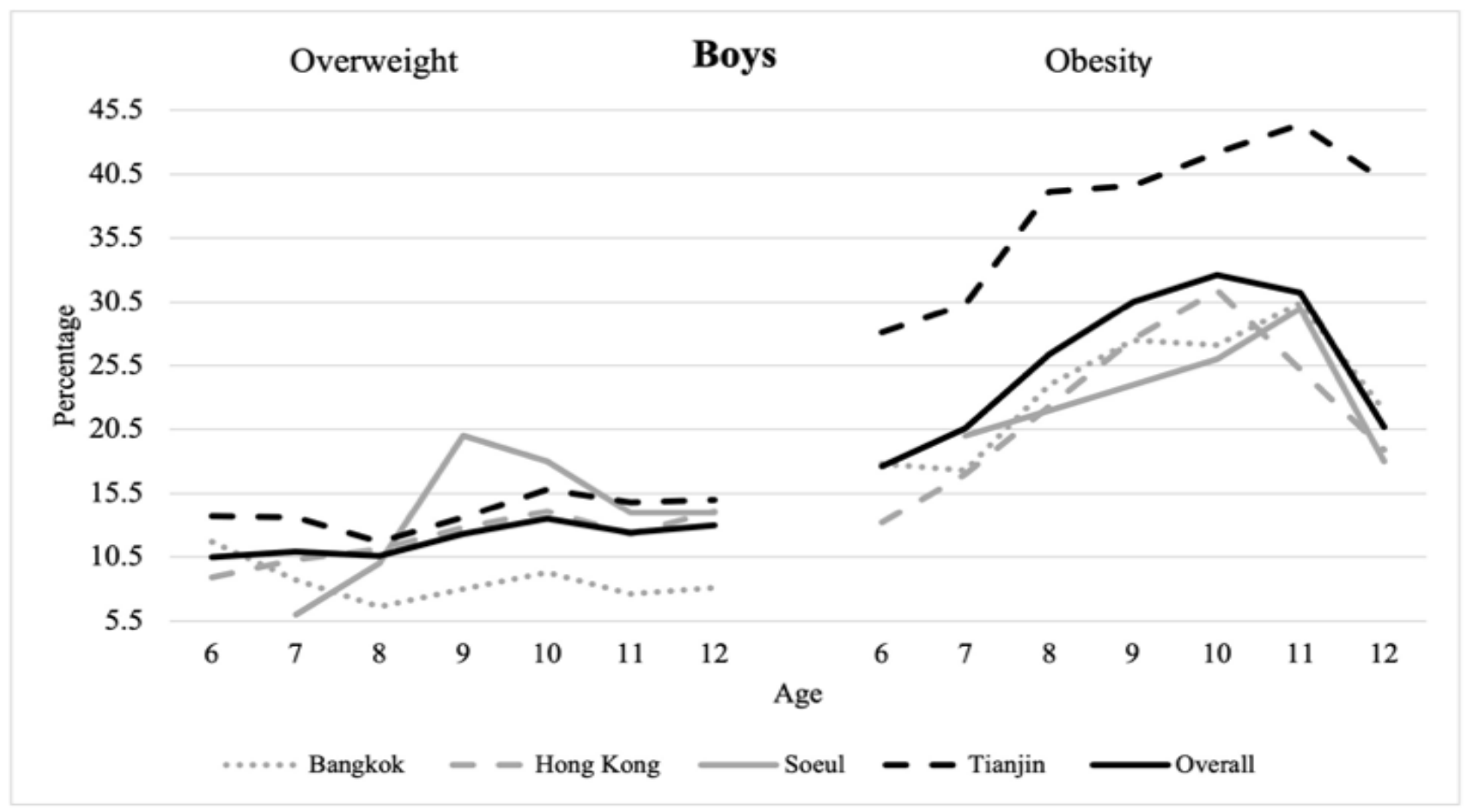

Figure 2. Development of overweight and obese categories in boys among cities 


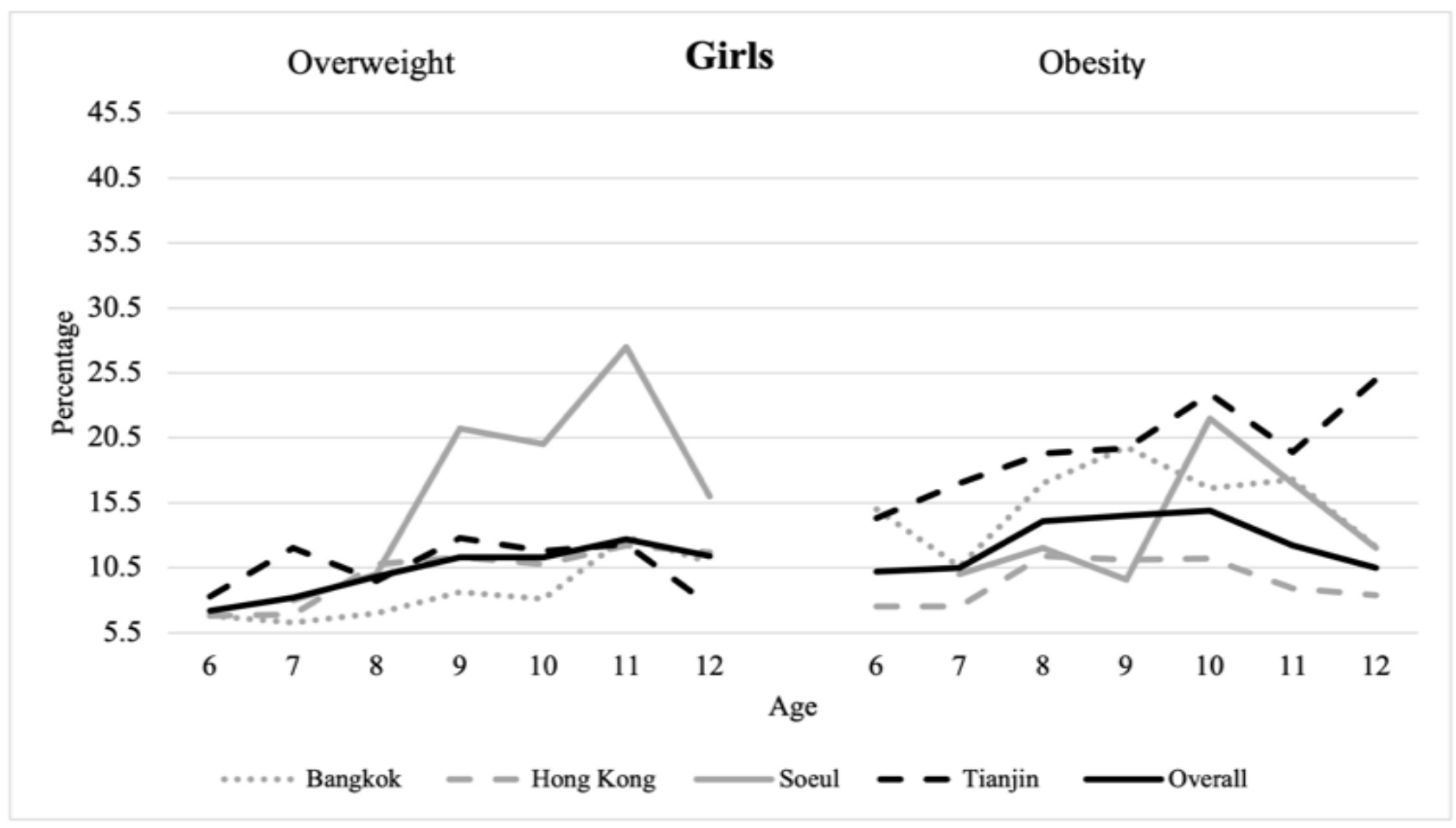

Figure 3. Development of overweight and obese categories of girls among cities

\section{Discussion}

The aims of this study were to explore the anthropometric parameters and BMI values of school-aged children from selected Asian cities, to investigate the proportion of children in different BMI categories, and to estimate overweight and obesity trends among children in order to gain a better understanding of the global problems of overweight and obesity. All mean values and statistical differences are presented in Table 2.

The boys and girls from Tianjin were significantly heavier, taller and had higher average BMIs values than children from Bangkok, Hong Kong, and Seoul. However, there was no significant difference in BMI between girls from Tianjin $\left(18 \mathrm{~kg} / \mathrm{m}^{2}\right)$ and girls from Seoul $\left(17.9 \mathrm{~kg} / \mathrm{m}^{2}\right)$. On the other hand, the least heavy boys $(33.5 \mathrm{~kg}$ ) were from Bangkok, and they also had the lowest height $(1.34 \mathrm{~m})$. A significant difference in height was observed between boys from Bangkok vs boys from Hong Kong $(1.39 \mathrm{~m})$, Seoul $(1.38 \mathrm{~m})$, and Tianjin $(1.42 \mathrm{~m})$. As with boys, girls from Bangkok were the shortest $(1.36 \mathrm{~m})$, followed by girls from Seoul (1.37 m), Hong Kong $(1.39 \mathrm{~m})$, and Tianjin $(1.41 \mathrm{~m})$. A significant difference in height was not found between girls from Seoul and girls from Bangkok and Hong Kong; however, there was a significant difference in height between girls from Bangkok and Hong Kong. This observation could be partially explained by the different ages of children in the sample; since children grow around 5-7 cm per year [24], a large age difference can cause significant variation in height. However, this logic could not be applied, because the children from Tianjin in our sample were the tallest and were the youngest. Our observations seem to indicate that the height is following the geographical distribution of the sample, with the pattern from short to tall going from south to north. This pattern raises the question of whether there is demographical or geographical issue related to height. Roser et al. [25] explored height across countries and regions and found that people from Europe and Central Asia were the tallest and people from South Asia are the shortest. This observation is consistent with that of another study in East Asia which reported that people were increasingly taller from the equator toward the north pole [26]. These studies indicate that height is a highly heritable trait, and there is still a large amount of data to explore [27]. Around $80 \%$ of height is determined by genetic factors, and around $20 \%$ can be due to environmental factors; for example, there is a correlation between height and socio-economic status [28]. Our observations related to height and geographical difference require further exploration.

The heaviest children, regardless of gender, were from Tianjin (40.1 kg boys and $36.6 \mathrm{~kg}$ girls), followed by Seoul (35.6 kg boys and $34.6 \mathrm{~kg}$ girls), Hong Kong (35.5 kg boys and $33.7 \mathrm{~kg}$ girls), Bangkok (33.5 kg boys and $33.6 \mathrm{~kg}$ girls). Boys and girls from Tianjin were significantly heavier than those from all other cities. The order of height and weight were the same among cities; however, there were changes in BMI. The children from Tianjin had greater BMI values $\left(19.3 \mathrm{~kg} / \mathrm{m}^{2}\right.$ boys and $18 \mathrm{~kg} / \mathrm{m}^{2}$ girls) then children from Seoul $\left(18.4 \mathrm{~kg} / \mathrm{m}^{2}\right.$ boys and $17.9 \mathrm{~kg} / \mathrm{m}^{2}$ girls), Bangkok (18.1 $\mathrm{kg} / \mathrm{m}^{2}$ boys and 
$17.7 \mathrm{~kg} / \mathrm{m}^{2}$ girls), and Hong Kong $\left(18 \mathrm{~kg} / \mathrm{m}^{2}\right.$ boys and $17.1 \mathrm{~kg} / \mathrm{m}^{2}$ girls). Girls from Tianjin were significantly heavier than those from Bangkok and Hong Kong, but not those from Seoul. Additionally, there was a significant difference in BMI between Hong Kong vs Bangkok and Seoul. In all variances, the anthropometric parameters seemed to have similar trends, which were that children from Tianjin were taller, heavier and had higher average BMI values followed by children from Seoul. The children from Bangkok were smaller and thinner, and children from Hong Kong had lower BMI values.

Zhang et al. [29] studied 441,306 adults from different Chinese provinces and found that the highest mean BMI was in Tianjin $\left(25.4 \mathrm{~kg} / \mathrm{m}^{2}\right)$, which is in agreement with the present study. The lowest BMIs in that study were in Hainan $\left(22.2 \mathrm{~kg} / \mathrm{m}^{2}\right)$, which is in the south part of China. Additionally, there was a higher prevalence of obese participants in Tianjin (12.2\%), and of overweight participants in Beijing (40.9\%), whereas the lowest rates of overweight and obesity were in Hainan (1.3\%) and Guangxi (14.6\%), respectively. The Zhang et al. [29] study discusses the north-south gradient, with the higher prevalence of overweight and obesity in northwest and northeast China and lower prevalence in southeast China.

The observations of Zhang et al. [29] are consistent with our study because children from southern cities had lower BMI values and were shorter and lighter, and those from northern cities, including Seoul, were taller and heavier. The proportions of children in each BMI category are shown in Figure 1. The most overweight and obese children were from Tianjin (52\% boys and $30.9 \%$ girls), followed by children from Seoul (37\% boys and 28.1\% girls). Similar proportions of overweight and obese boys and girls were observed in Hong Kong (34.8\% boys and $20 \%$ girls) and Bangkok (33\% boys and 24.7\% girls).

Helble and Sato [30] investigated overweight and obesity issues among Asian and Pacific countries and found that the lowest overall prevalence of overweight and obesity in the year 2013 was in Southeast Asia (26.3\%), followed by South Asia (28.9\%). The highest prevalence of overweight and obesity was in Central Asia (49.25\%) and Pacific (60.60\%). Compared with the children from Tianjin in our study, children in Shanghai had a higher overall prevalence of overweight and obesity ( $52 \%$ vs $69 \%$ for boys and $31 \%$ vs $58 \%$ for girls in our study vs. the Helble and Sato [30] study, respectively). Martinson et al. [31] found that boys were more likely to be overweight and obese than girls ( $40 \%$ vs $49 \%$ for overweight and $18 \%$ vs $20 \%$ for obesity). These were similar results to our study; however, Martinson et al. [31] used a different BMI reference. A recent study reported a very low prevalence of overweight (1.91\%) and obesity $(.89 \%)$ in children from South Asia under 5 years of age [32].

Differences in weight and BMI are related to different living conditions, such as family socioeconomic status
[33], economy of the country [34], or geographic location [35]. For example, urban children (who usually have better nutrition) are taller and heavier than their rural counterparts $[36,37]$. A difference in height and weight between rural and urban children can be seen in China and in regions such as the Andes, central Latin America, and Vietnam [36]. Although height is strongly correlated with living conditions and standards [27], it is also strongly heritable. One investigation identified a positive association between obese parents and their children aged 4-11 years [38]. Parental obesity has been identified as one of the main risk factors for children's obesity; it is likely that children of obese parents will be obese or have a considerably higher risk of obesity [39].

Yao and Hillemeister [40] reported that Chinese parents and grandparents constantly worry that their children and grandchildren are not eating enough, and $72 \%$ of sample of Chinese mothers believed that their overweight children were normal or even underweight. The increasing prevalence of overweight and obesity has been well-documented in many studies. For example, Ogden et al. [41] presented results from more than 10 years of research on overweight and obesity among children and adolescents in the United States aged 2-19 years. Among children aged 6-11 years, obesity increased from $11.3 \%$ during $1988-1994$ to $19.6 \%$ during $2007-2008$.

Our study takes a different view on the changing patterns across ages. This study attempted to distinguish the periods of age when the increases in these BMI categories occurred. Figure 2 and Figure 3 display the development of overweight and obesity of boys and girls from selected cities from ages 6-12. The prevalence of obesity decreased with age only in girls; in the rest of the observations the prevalence increased with age. One noteworthy observation was that, although the increases and decreases in prevalence of overweight and obesity varied among the cities, overall, the critical periods for the development of overweight and obesity were from 8-10 years and from 7-10 years, respectively, and the rates dropped slightly after age 10 .

Few studies have investigated these issues, and most reports have compared overweight and obesity in the same ages. Our study is consistent with a study of Japanese children by Matsushita et al. [14] that showed that the clearest increasing trend of overweight and obesity happened between ages 9-11 for children of both sexes, although this study recorded age 7 and 8 as critical for increasing the overweight and obesity among children. Another study found that BMI z-scores of children from the United Kingdom mainly increased between 7-9 years of age [42]. Additionally, similarly to other studies [31, 43, 44]; this study observed that boys represented higher proportions of the overweight and obesity categories. Overweight and obesity tend to increase with age. The proportion of overweight and obese children is serious and is more critical in boys than in girls. It is necessary to 
control and monitor these trends and help children to stay fit and maintain healthy body weights and BMIs. It is critically important to determine and develop the best ways and strategies to decrease or stop increasing overweight and obesity. Knowing the critical age period for the development of overweight and obesity can facilitate the creation of strategies for preventing them. If the concept of critical age is accurate, there is a strong need for children and their parents to be more aware of healthy activities, particularly from ages 8-10. Based on the results of our study, it recommends having more time spent in physical activity among children aged 8-10 years, control of calorie intake, and improvement in diet to prevent overweight and obesity.

\section{Conclusions}

Our findings indicated a significant difference in height, weight, and BMI between boys and girls from Tianjin and other cities that were involved in this investigation. Children of both sexes from Tianjin were significantly taller, heavier, and had higher BMI values than children from Bangkok, Hong Kong, and Seoul. The next group of children that had heavier and taller condition were from Seoul. Tianjin also had higher proportions of children who were overweight and obese, followed by children from Seoul. On other hand, children from Bangkok were shorter and lighter, and children from Hong Kong had lower BMI values. These findings could demonstrate a geographical association with height, body weight, BMI and prevalence of selected BMI categories. Similar observation on geographical association was also discussed by Sawyer [45] in her paper of global growth trends in school-aged children and adolescent in Lancet. In our study overweight and obesity were found to be increasing among children aged 6-12 years, whereas obesity decreased from 6-12 years only in girls and only by $1 \%$. Boys were found to be at higher risk of obesity than girls in each age group. The critical age for overweight and obesity among males and females in our sample appeared to range from 8-10 and from 7-10 years, respectively. We encourage authorities to develop effective physical activity programs and interventions to offer and ensure that children have enough physical activities available per day. The monitoring system of physical activity among children and their 'health status' is needed to fight with an increase in overweight and obesity problem.

\section{REFERENCES}

[1] A. A. Hedley, C. L. Ogden, C.L. Johnson, M. D. Carroll, L. R. Curtin and K. M. Flegal. "Prevalence of overweight and obesity among US children adolescents and adults, 1999-2002," Journal of American Medical Association, vol. 291, no. 23, pp. 2847-2850, 2004. DOI: 10.1001/jama.291.23.2847.

[2] M. Ng, T. Fleming, M. Robinson, B. Thomson, N. Graetz, C. Margono, E. C. Mullany, ... E. Gakidou. "Global, regional and national prevalence of overweight and obesity in children and adults during 1980 - 2013: a systematic analysis for the Global Burden of Disease Study 2013," The Lancet, vol. 384, pp. 766-781, 2014. DOI: 10.1016/S0140-6736(14)60460-8.

[3] World Health Organization, "Obesity and Overweight." World Health. Organizationhttp://www.who.int/mediacentr e/factsheets/fs311/en/ (Accessed Nov. 2020).

[4] P. M. Bernard. "Health Management Model: A Case Study for Success,” Universal Journal of Public Health, vol. 9, no. 2, pp. 51-56, 2021. DOI: 10.13189/ujph.2021.090203.

[5] A. Hussain, K. Mahawar, Z. Xia, W. Yang, S. EL-Hasani. "Obesity and mortality of COVID-19. Meta-analysis," Obes Res Clin Pract, vol. 14, no. 4, pp. 295-300, 2020. DOI: 10.1016/j.orcp.2020.07.002.”

[6] M. F. Faienza, D. Q. H. Wang, G. Frühbeck, G. Garruti, P. Protincasa, "The dangerous link between childhood and adulthood predictors of obesity and metabolic syndrome," Internal and Emergency Medicine, vol. 11, pp. 175-182, 2016, DOI: https://link.springer.com/article/10.1007/s1173 9-015-1382-6.

[7] B. M. Popkin, C. M. Doak, "The obesity epidemic is a worldwide phenomenon," Nutrition Review, vol. 56, no. 4, pp. 106-114, 1998. DOI: 10.1111/j.1753-4887.1998.tb017 22.x.

[8] A. Ramachandran, C. Snehalatha, "Rising burden of Obesity in Asia," Journal of obesity, Article 868573, 2010. DOI: 10.1155/2010/868573.

[9] W. S. Cheong, "Overweight and Obesity in Asia." Gen Re. http://media.genre.com/documents/uwfocus14-2-cheong-e n.pdf (Accessed Dec. 2020).

[10] Y. Chen, Q. Peng, Y. Yang, S. Zheng, Y. Wang, W. Lu, "The prevalence and increasing trends of overweight, general obesity, and abdominal obesity among Chinese adults: a repeated cross-sectional study," BMC Public Health, vol. 19, article no. 1293, 2019. https://doi.org/10.1186/s12889-019-7633-0.

[11] Y. Wang, H. Xue, M. Sun, X. Zhu, L. Zhao, Y. Yang, "Prevention and control of obesity in China," The Lancet Global Health, vol. 7, no. 9, pp. e1166-e1167, 2019. https://doi.org/10.1016/S2214-109X(19)30276-1

[12] A. Misra, "Ethnic-Specific Criteria for classification of Body Mass Index: A Perspective for Asian Indians and American Diabetes Association Position Statement," Diabetes Technology \& Therapeutics, vol. 17, no. 9, pp. 667-671, 2015. DOI: 10.1089/dia.2015.0007.

[13] WHO expert consultation. "Appropriate Body Mass Index for Asian population and its implications for policy and intervention strategies," Lancet, vol. 10, no. 363, pp. 157-163, 2004. DOI: 10.1016/S0140-6736(03)15268-3.

[14] Y. Matsushita, N. Yoshiike, F. Kaneda, K. Yoshita, H. 
Takimoto, "Trends in Childhood Obesity in Japan over the Last 25 years from the National Nutrition Survey," Obesity research, vol. 12, no. 2, pp. 205-2014, 2014. DOI: 10.1038/oby.2004.27.

[15] Centers for Disease Control and Prevention, "Overweight and Obesity" Centers for Disease Control and Prevention. https://www.cdc.gov/obesity/childhood/causes.html (Accessed Dec. 2020).

[16] Mayo Clinic, "Childhood obesity" Mayo Clinic. https://www.mayoclinic.org/diseases- conditions/childhood -obesity/symptoms-causes/syc-20354827 (Accessed Jan. 2021).

[17] M. F. Rolland-Cachera, M. Deheeger, M. Maillot, F. Bellisle. "Early adiposity rebound causes and consequences for obesity in children and adults," International Journal of Obesity, vol. 30, no. 4, pp. 11-17, 2006. DOI: 10.1038/sj.ijo.0803514.

[18] Y. Wang, T. Lobstein, "Worldwide trends in childhood overweight and obesity," International Journal of Pediatric Obesity, vol. 1, no. 1, pp. 11-25, 2006. DOI: 10.1080/17477160600586747

[19] M. F. Rolland-Cachera, M. Deheeger, M. Guilloud-Bataille, P. Avons, E. Patois, M. Sempe, "Tracking the development of adiposity from one month of age to adulthood, " Annals of Human Biology, vol. 14, no. 3, pp 219-229, 1987. DOI: 10.1080/03014468700008991.

[20] W. H. Dietz, "Critical periods in childhood for the development of obesity," The American Journal of Clinical Nutrition, vol. 59, no. 5, pp. 955-959, 1994. DOI: 10.1093/ajcn/59.5.955.

[21] M. Geserick, M. Vogel, R. Gausche, T. Lipek, U. Spielau, E. Keller, ... A. Korner, "Acceleration of BMI in Early Childhood and Risk of Sustained Obesity," The New England Journal of Medicine, vol. 379, pp. 1303-1312, 2018. DOI: 10.1056/NEJMoa1803527.

[22] C. Padez, T. Fernandes, I. Mourao, P. Moreira, V. Rosado, "Prevalence of overweight and Obesity in 7 - 9 years old Portuguese Children: Trends in Body Mass Index from 1970 - 2002," American Journal of Human Biology, vol. 16, no. 6, pp. 670-678, 2004. https://doi.org/10.1002/ajhb.200 80 .

[23] World Health Organization, "BMI-for-age (5-19 years)." World Health Organization. https://www.who.int/growthre f/who2007_bmi_for_age/en/ (Accessed: Oct. 2020).

[24] M. L. Gavin, "Growth and Your 6- to 12-Year-Old." KidsHealth. https://kidshealth.org/en/parents/growth-6-12. html (Accessed: Nov.2020).

[25] M. Roser, C. Appel, H. Ritchie, "Human Height." Our World in Data. https://ourworldindata.org/human-height (Accessed: Jan. 2020).

[26] L. Geggel, "Where Do the World's Tallest and Shortest People live?" Live Science. https://www.livescience.com/5 5580-tallest-shortest-people-in-world.html (Accessed: Jan. 2020).

[27] E. Marouli, M. Graff, C. Medina-Gomez, K. S. A. R. Wood, T. R. Kjaer, ... G. Lettre. "Rare and low-frequency coding variants alter human adult height," Nature, vol. 542 no.
7640, pp. 186-190, 2017. DOI: 10.1038/nature21039.

[28] B. P. McEvoy, P. M. Visscher, "Genetics of human height," Economics \& Human Biology, vol. 7, no. 3, pp. 294-306, 2009. DOI: 10.1016/j.ehb.2009.09.005.

[29] L. Zhang, Z. Wang, X. Wang, Z. Chen, L. Shao, Y. Tian, C. Zheng, S. Li, M. Zhu, R. Gao, "Prevalence of overweight and obesity in China: Results from a cross-sectional study of 441 thousand adults, 2012-2015," Obesity Research \& Clinical Practice, vol. 14, no. 2, pp. 119-126, 2020. https://doi.org/10.1016/j.orcp.2020.02.005.

[30] M. Helble, A. Sato, "Wealthy But Unhealthy, Overweight and Obesity in Asia and the Pacific: Trends, Costs, and Policies for Better Health." ADBInstitute. https://www.adb.org/sites/default/files/publication/432536/ adbi-wealthy-unhealthy-overweight-obesity-asia-pacific.pd f (Accessed: Jan. 2021).

[31] M. L. Martinson, Y. Chang, W. Han, J. Wen, "Child Overweight and Obesity in Shanghai, China: Contextualizing Chinese Socioeconomic and Gender Differences," International Journal of Behavioral Medicine, vol. 25, no. 1, pp. 141-149, 2020. DOI: 10.1007/s12529-017-9688-6.

[32] G. Bishwajit, S. Yaya, "Overweight and obesity among under-five children in South Asia," Child and Adolescent Obesity, vol. 3, no. 1, pp. 105-121, 2020. DOI: 10.1080/2574254X.2020.1769992.

[33] S. Newton, D. Braithwaite, T. F. Akinyemiju, "Socio-economic status over the life course and obesity: Systematic review and meta-analyses" Plos One, vol. 12 no. 5, pp. e0177151, 2017. DOI: 10.1371/journal.pone.017715 1.

[34] T. Templin, T. C. O. Hashiguchi, B. Thomson, J. Dieleman, and E. Bendavid. "The overweight and obesity transition from the wealthy to the poor in low- and middle-income countries: A survey of Household data from 103 countries," Plos Med, vol. 16, no. 11, pp. e1002968, 2019. https://doi.org/10.1371/journal.pmed.1002968

[35] G. Erdei, M. Bakacs, É. Illés, B. Nagy, C. Kaposvári, E. Mák, E. S. Nagy, Z. Cserhát, V. A. Kovács, "Substantial variation across geographic regions in the obesity prevalence among 6-8 years old Hungarian children (COSI Hungary 2016)," BMC Public Health, vol. 18, no. 611, 2018. https://doi.org/10.1186/s12889-018-5530-6.

[36] Ch. J. Paciorek, G. A. Stevens, M. M. Finucane, M. Ezzati, Nutrition Impact Model Study Group (Child Growth). "Children`s height and weight in rural and urban populations in low-income and middle-income countries: a systematic analysis of population - representative data," The Lancet. Global Health, vol. 1, no. 5, pp. e300-e309, 2013. DOI: 10.1016/S2214-109X(13)70109-8.

[37] K. Fox, T. B. Heaton, "Child nutritional status by rural/urban residence: a cross-national analysis," Journal of rural Health, vol. 28, no. 4, pp. 380-391, 2012. DOI: 10.1111/j.1748-0361.2012.00408.x.

[38] C. Semmler, J. Ashcroft, C. H. M. van Jaarsveld, S. Carnell, J. Wardle, "Development of Overweight in children in relation to Parental Weight and socioeconomic status," Obesity, vol. 17, no. 4, pp. 814-820, 2009. Doi: 10.1038/oby.2008.621. 
[39] V. Burke, L. J. Beilin, D. Dunbar, "Family lifestyle and parental body mass index as predictors of body mass index in Australian children: a longitudinal study. International," Journal of Obesity and Related Metabolic Disorders, vol. 25, no. 2, pp. 147-157, 2001. DOI: 10.1038/sj.ijo.0801538.

[40] N. Yao, M M. Hillemeier, "Weight status in Chinese children: Maternal perceptions and child self-assessments," World Journal of Pediatrics, vol. 8, no. 2, pp. 129-135, 2012. DOI: 10.1007/s12519-012-0346-4.

[41] C. L. Ogden, M. D. Carroll, H. G. Lawman, Ch. D. Fryar, D. Kruszon-Moran, B. K. Kit, and K. M. Flegal. "Trends in Obesity Prevalence among children and Adolescents in the United States, 1988 - 1994 through 2013 - 2014," JAMA, vol. 315, no. 21, pp. 2292-2299, 2016. DOI:10.1001/jama.2016.6361.

[42] A. R. Hughes, A. Sherriff, D. A. Lawlor, A. R. Ness, J. J. Reilly. "Timing of excess weight gain in the Avon Longitudinal Study of Parents and Children (ALSPAC),"
Paediatrics, vol. 127, no. 3, pp. e730-e736, 2011. DOI https://doi.org/10.1542/peds.2010-0959.

[43] H. He, L. Pan, J. Du, F. Liu, Y Jin, J. Ma, L. Wang, P. Jia, Z. $\mathrm{Hu}, \mathrm{G}$. Shan. "Muscle fitness and its association with body mass index in children and adolescents aged 7-18 years in China: a cross-sectional study," BioMed central Pediatrics, vol. 19, no. 101, 2019. https://doi.org/10.1186/s12887-019 $-1477-8$.

[44] V. Živkovic, L. Todorovska, L. A. Veličkovska, S. Gontarev, R. Kalac. "Relationships between overweight, obesity and physical fitness of thirteen and fourteen-year-old Macedonian adolescent," SportLogia, vol. 10, no. 2, pp. 106-115, 2014. DOI: 10.5550/sgia.141002.e n.007Z.

[45] S. M. Sawyer, "Global growth trends in school-aged children and adolescent," The Lancet, vol. 396, no. 10261, pp. 1465-1467, 2020. https://doi.org/10.1016/S0140-6736( 20)32232-7. 